\title{
Shape Differences in the Corpus Callosum in First- Episode Schizophrenia and First-Episode Psychotic Affective Disorder
}

\section{Citation}

Frumin, Melissa, Polina Golland, Ron Kikinis, Yoshio Hirayasu, Dean F. Salisbury, John Hennen, Chandlee C. Dickey, et al. 2002. Shape Differences in the Corpus Callosum in First-Episode Schizophrenia and First-Episode Psychotic Affective Disorder. AJP 159, no. 5: 866-868. doi:10.1176/appi.ajp.159.5.866.

\section{Published Version}

doi:10.1176/appi.ajp.159.5.866

\section{Permanent link}

http://nrs.harvard.edu/urn-3:HUL.InstRepos:28520524

\section{Terms of Use}

This article was downloaded from Harvard University's DASH repository, and is made available under the terms and conditions applicable to Other Posted Material, as set forth at http:// nrs.harvard.edu/urn-3:HUL.InstRepos:dash.current.terms-of-use\#LAA

\section{Share Your Story}

The Harvard community has made this article openly available.

Please share how this access benefits you. Submit a story.

Accessibility 


\title{
Shape Differences in the Corpus Callosum in First-Episode Schizophrenia and First-Episode Psychotic Affective Disorder
}

\author{
Melissa Frumin, M.D., Polina Golland, Ph.D., Ron Kikinis, M.D., Yoshio Hirayasu, M.D., \\ Ph.D., Dean F. Salisbury, Ph.D., John Hennen, Ph.D., Chandlee C. Dickey, M.D., Mark \\ Anderson, M.S., Ferenc A. Jolesz, M.D., W. Eric L. Grimson, Ph.D., Robert W. McCarley, \\ M.D., and Martha E. Shenton, Ph.D. \\ Clinical Neuroscience Division, Laboratory of Neuroscience, Consolidated Department of \\ Psychiatry, Harvard Medical School and VA Boston Healthcare System-Brockton Division; Artificial \\ Intelligence Laboratory, Massachusetts Institute of Technology, Cambridge, Mass.; Surgical \\ Planning Laboratory, MRI Division, Department of Radiology, Brigham and Women's Hospital and \\ Harvard Medical School, Boston; Cognitive Neuroscience Laboratory and Biostatistics Laboratory, \\ McLean Hospital, Belmont, Mass.
}

\begin{abstract}
Objective-The corpus callosum, the largest white matter tract in the brain, is a midline structure associated with the formation of the hippocampus, septum pellucidum, and cingulate cortex, which have been implicated in the pathogenesis of schizophrenia. Corpus callosum shape deformation, therefore, may reflect a midline neurodevelopmental abnormality.
\end{abstract}

Method-Corpus callosum area and shape were analyzed in 14 first-episode psychotic patients with schizophrenia, 19 first-episode psychotic patients with affective disorder, and 18 normal comparison subjects.

\begin{abstract}
Results-No statistically significant corpus callosum area differences between groups were found, but there were differences in the structure's shape between the patients with schizophrenia and the comparison subjects. A correlation between width and angle of the corpus callosum was found in patients with affective disorder.
\end{abstract}

Conclusions-Corpus callosum shape abnormalities in first-episode psychotic patients with schizophrenia may reflect a midline neurodevelopmental abnormality.

The corpus callosum, the largest white matter tract in the brain, is a midline structure whose development is associated with the formation of the hippocampus, septum pellucidum, and cingulate cortex, all of which have been implicated in the pathogenesis of schizophrenia (1). Moreover, the development of cortical-cortical and subcortical-cortical connections determines the pattern of brain growth and shape (2). Deformations in corpus callosum shape, therefore, may reflect a midline neurodevelopmental abnormality. Recent studies by DeQuardo et al. (3) and Downhill et al. (4) found corpus callosum shape alterations in schizophrenia.

We evaluated corpus callosum area and shape in first-episode psychotic patients with schizophrenia, first-episode psychotic patients with affective disorder, and normal comparison subjects. We included psychotic patients with affective disorder to assess the specificity of

Copyright $(92002$ American Psychiatric Association.

Address reprint requests to Dr. Shenton or Dr. McCarley, Department of Psychiatry-116A, VA Boston Healthcare System-Brockton Division, 940 Belmont St., Brockton, MA 02301; martha_shenton@hms.harvard.edu; robert_mccarley@hms.harvard.edu.. 
corpus callosum shape deformations to schizophrenia. For our shape measure we used a twodimensional skeletonization model employed in the field of computer vision (5).

\section{Method}

Subjects were 14 first-episode psychotic inpatients with schizophrenia (11 men, three women), 19 first-episode psychotic inpatients with affective disorder (14 men, five women), and 18 comparison subjects (16 men, two women). The diagnoses of the patients with affective disorder were bipolar disorder, mania ( $\mathrm{N}=12)$, bipolar disorder, mixed $(\mathrm{N}=4)$, and major depression ( $\mathrm{N}=3)$. Comparison subjects were recruited through newspaper advertisements. Diagnostic information and inclusion and exclusion criteria are detailed elsewhere (6). All subjects provided written informed consent before study participation.

The mean ages of the study subgroups were 28.1 years $(\mathrm{SD}=7.8)$ for the schizophrenia group, $25.8(\mathrm{SD}=5.8)$ for the affective disorder group, and $24.5(\mathrm{SD}=4.5)$ for the comparison group $(\mathrm{F}=1.54, \mathrm{df}=2,48, \mathrm{p}=0.22)$. The socioeconomic status of patients with schizophrenia was lower than that of the comparison subjects, in accord with the effects of their illness $(\mathrm{F}=4.74, \mathrm{df}=2$, $48, \mathrm{p}=0.01$ ). Parental socioeconomic status for the schizophrenia group was lower than that of the comparison group and the affective disorder group $(\mathrm{F}=5.83, \mathrm{df}=2,48, \mathrm{p}=0.005)$, though all groups ranged between middle and upper class.

Patients were assessed with the Brief Psychiatric Rating Scale (BPRS), the Global Assessment Scale (GAS), and the Mini-Mental Status Examination (MMSE).

Magnetic resonance (MR) images were acquired on a 1.5-T General Electric system (General Electric Medical Systems, Milwaukee) (echo time [TE] $=5 \mathrm{msec}$, repetition time [TR]=35 msec, one repetition, nutation angle $=45^{\circ}$, field of view $=24 \mathrm{~cm}$, acquisition matrix $=256 \times 256 \times 124$, with dimensions $0.9375 \times 0.9375 \times 1.5$ ) (for additional details, see Hirayasu et al. [6]).

For MR post-processing image analysis of area, a midsagittal slice was chosen that included the clearest view of the corpus callosum, aqueduct, tectum, septum pellucidum, and falx. The best midsagittal slice and two slices laterally on each side of the midsagittal slice ( $\mathrm{N}=5$ slices) were then segmented. Area was computed by summing pixels in each slice for the entire corpus and for four sections (genu, midbody, isthmus, and splenium [7]. Group differences in the best midsagittal slice, the average of five slices, and the subsections were compared by using analysis of variance. Analyses of covariance (ANCOVA) were performed to control for the effects of age and overall head/brain size.

For MR post-processing image analysis of shape, a two-dimensional skeleton of the corpus callosum was extracted by using the same best midsagittal slice and one slice laterally on each side of the midsagittal slice ( $\mathrm{N}=3$ slices) (top part of Figure 1). Width and curvature were measured at eight equidistant points. Likelihood of group membership was assessed by using a classification analysis in which we examined each of the two-by-two classifications: normal versus affective disorder, normal versus schizophrenia, and affective disorder versus schizophrenia. We used bootstrap methods to obtain standard errors for the two-by-two classifications statistics. We obtained 100 bootstrap resampling repetitions, yielding chi-square statistics $(\mathrm{df}=16)$ with standard error estimates on the basis of the 100 bootstrap repetitions.

\section{Results}

No statistically significant differences in area between the groups were found for the best midsagittal slice $(\mathrm{F}=1.03, \mathrm{df}=2,48, \mathrm{p}=0.54)$, average of five slices $(\mathrm{F}=1.92, \mathrm{df}=2,48, \mathrm{p}=0.18)$, or subdivisions of the genu $(\mathrm{F}=0.14, \mathrm{df}=2,48, \mathrm{p}=0.72)$, midbody $(\mathrm{F}=1.24, \mathrm{df}=2,48, \mathrm{p}=0.29)$, isthmus $(\mathrm{F}=1.17, \mathrm{df}=2,48, \mathrm{p}=0.30)$, or splenium $(\mathrm{F}=0.20, \mathrm{df}=2,48, \mathrm{p}=0.66)$. Using ANCOVA 
to control for the effects of age and size of the intracranial cavity, we found no significant differences in area between groups. As there are gender differences in corpus callosum size (7), we excluded 10 female subjects in one analysis; there were no area differences between the schizophrenia and comparison groups $(\mathrm{F}=0.26, \mathrm{df}=1,25, \mathrm{p}=0.61)$ or between the affective disorder and comparison groups $(\mathrm{F}<0.01, \mathrm{df}=1,28, \mathrm{p}=0.96)$. For all groups, there were no statistically significant correlations between area and lateral ventricular volumes, nor between area and MMSE, BPRS, or GAS scores or chlorpromazine equivalents of medication received by the subjects.

For analysis of shape, an angles-and-widths multinomial regression model was used (on the basis of the eight equidistant points used to extract the skeleton image) to obtain the classification data for examining each of three two-by-two classification tables. The three twoby-two contrasts (comparison versus affective disorder, comparison versus schizophrenia, and affective disorder versus schizophrenia) were estimated by bootstrap methods, with chi-square statistics $(\mathrm{df}=16)$ defined as the mean chi square among all 100 bootstrap repetitions. The contrast between the comparison and schizophrenia groups was statistically significant $\left([\mathrm{chi}]^{2}=30.6, \mathrm{df}=16, \mathrm{p}<0.02\right)$. The other contrasts were not statistically significant (comparison versus affective disorder: $[\mathrm{chi}]^{2}=19.3, \mathrm{df}=16, \mathrm{p}=0.25$; affective disorder versus schizophrenia: $\left[_{\mathrm{chi}}{ }^{2}=20.3, \mathrm{df}=16, \mathrm{p}=0.21\right.$ ). The lower part of Figure 1 shows prototypic corpus callosum shapes for each diagnostic group.

For shape measures, there were no statistically significant correlations of average angle and width with area, lateral ventricular volumes, or scores on the clinical measures (MMSE, BPRS, GAS). In the affective disorder group only, as the width decreased, the angle decreased ( $\mathrm{r}=0.89$, $\mathrm{df}=18, \mathrm{p}<0.02$ ), i.e., as the corpus callosum width narrowed, the shape became more curved.

\section{Discussion}

Corpus callosum area and shape were evaluated in first-episode psychotic patients with schizophrenia and with affective disorder and normal comparison subjects by using twodimensional shape analyses. No differences were found in corpus callosum area among the three groups, although differences in shape were observed between the patients with schizophrenia and the comparison subjects. In addition, in the affective disorder group only, as corpus callosum width narrowed, the angle decreased, resulting in a more curved shape. These findings, while intriguing, need to be confirmed in an independent group of study subjects. Moreover, an insult to the developing brain during the time of rapid growth of the corpus callosum may partially account for these findings, although this explanation is speculative.

\section{Acknowledgments}

Supported by an Ethel Dupont-Warren Fellowship Award; a VA Psychiatry/Neuroscience Research Fellowship Award; the Stanley Scholars Mentor Program for Student Fellowships; NIH grants R01-RR-11747 and P41-RR-1321; NIMH grants MH-50740, MH-01110, and MH-40799; the VA Center for Clinical and Basic Neuroscience Studies of Schizophrenia; VA Merit Awards; a Young Investigator Award from the National Alliance for Research on Schizophrenia and Depression; National Science Foundation grant IIS9610249; and Mitsubishi Electric Research Laboratories.

The authors thank Chris Dodd, Alaka Pellock, and Marie Fairbanks for assistance with the study.

\section{References}

1. Shenton ME, Dickey CC, Frumin M, McCarley RW. A review of MRI findings in schizophrenia. Schizophr Res 2001;49:1-52. [Medline Link] [BIOSIS Previews Link] [Context Link]. [PubMed: 11343862] 
2. Van Essen DC. A tension-based theory of morphogenesis and compact wiring in the central nervous system. Nature 1997;385:313-318. [Medline Link] [BIOSIS Previews Link] [Context Link]. [PubMed: 9002514]

3. DeQuardo JR, Keshavan MS, Bookstein FL, Bagwell WW, Green WD, Sweeney JA, Haas GL, Tandon R, Schooler NR, Pettegrew JW. Landmark-based morphometric analysis of first-episode schizophrenia. Biol Psychiatry 1999;45:1321-1328. [Medline Link] [PsycINFO Link] [BIOSIS Previews Link] [Context Link]. [PubMed: 10349039]

4. Downhill J, Buchsbaum MS, Wei T, Spiegel-Cohen J, Hazlett EA, Haznedar MM, Silverman J, Siever LJ. Shape and size of the corpus callosum in schizophrenia and schizotypal personality disorder. Schizophr Res 2000;42:193-208. [Medline Link] [PsycINFO Link] [BIOSIS Previews Link] [Context Link]. [PubMed: 10785578]

5. Golland P, Grimson WEL. Fixed topology skeletons, in Computer Vision and Pattern Recognition 2000. Hilton Head Island, SC, IEEE Computer Society 2000:10-17. [Context Link].

6. Hirayasu Y, Shenton ME, Salisbury DF, Dickey CC, Fischer IA, Mazzoni P, Kisler T, Arakaki H, Kwon JS, Anderson JE, Yurgelun-Todd D, Tohen M, McCarley R. Lower left temporal lobe MRI volumes in patients with first-episode schizophrenia compared with psychotic patients with firstepisode affective disorder and normal subjects. Am J Psychiatry 1998;155:1384-1391. [Fulltext Link] [Medline Link] [PsycINFO Link] [BIOSIS Previews Link] [Context Link]. [PubMed: 9766770]

7. Witelson SF. Hand and sex differences in the isthmus and genu of the human corpus callosum: a postmortem morphological study. Brain 1989;112(part 3):799-835. [Medline Link] [BIOSIS Previews Link] [Context Link]. [PubMed: 2731030] 


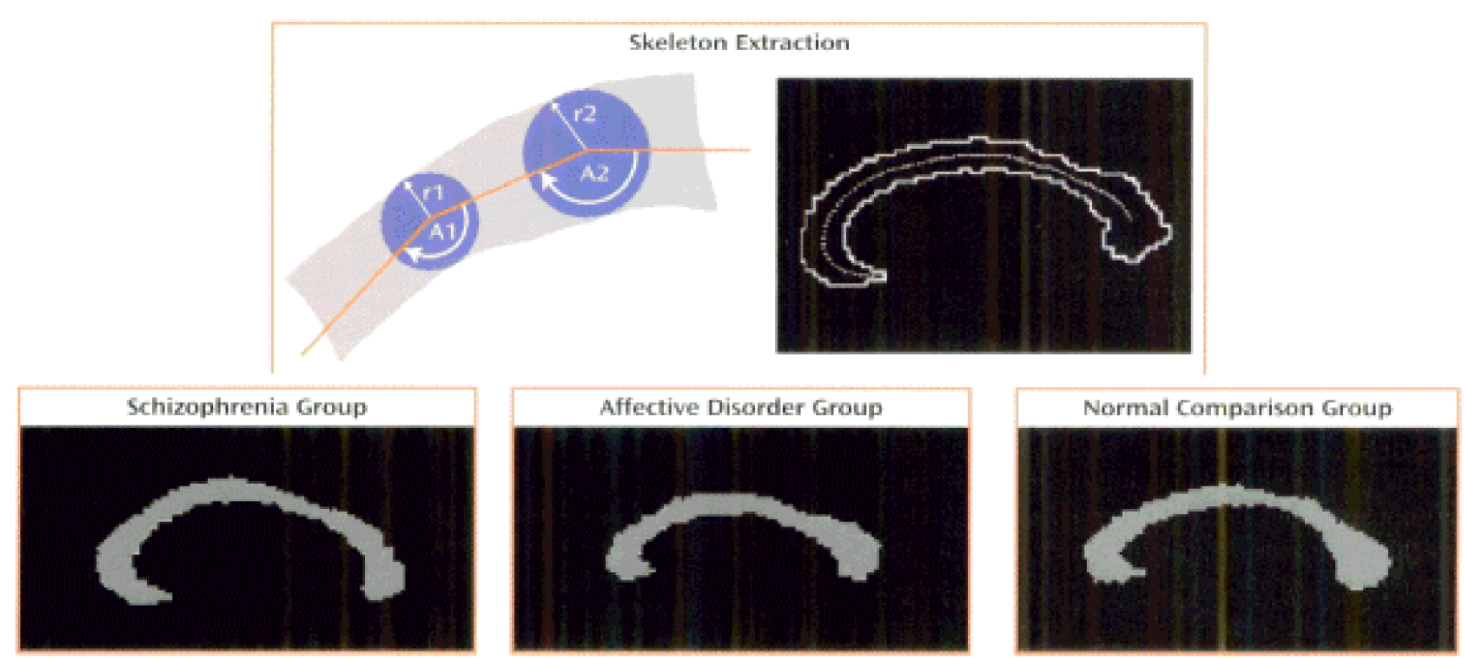

a The skeleton was derived by calculating the points along the corpus callosum that were equal to the distance from a given point within the structure to the closest point on the outline of the corpus callowm (e. g. distances 11 and $r 2$ in the top part of the figure). Specifically, a disk, in blue in the figure (e.g.. A1 and A2) is placed inside the segmented corpus callosum and expanded until it touches the outline of the corpus callosum on opposite points of the outline. The center of this expanded disk thus defines a point that, combined with the other points defined in the same way, becomes a skeleton, or curve, that defins the shape in two dimensions. Skeletons were extracted from the best midsagitial slice and from one slice baterally on each side of the midsagittal slice to increase reliability in shape description. In the lower part of the figure, the prototypic shapes of the corpus callosum in the three diagnostic groups show the greatest difference between groups on the basis of angle and width measurements at the eight sampled points.

FIGURE 1.

Process of Skeleton Extraction and Prototypic Shapes of the Corpus Callosum in First-Episode Psychotic Patients With Schizophrenia or Affective Disorder and Normal Comparison Subjects $^{\mathrm{a}}$ 